\title{
Distrofia muscular nutricional em ovinos na Paraíba ${ }^{1}$
}

\author{
Sara Lucena Amorim² ${ }^{2}$, Alex Cicinato P. de Oliveira ${ }^{3}$, Franklin Riet-Correa ${ }^{4 *}$, Sara \\ Vilar Dantas Simões ${ }^{4}$, Rosane M.T. Medeiros ${ }^{4}$ e Inácio José Clementino ${ }^{2}$
}

\begin{abstract}
Amorim S.L., Oliveira A.C.P., Riet-Correa F., Simões S.V.D., Medeiros R.M.T. \& Clementino I.J. 2005. [Nutritional muscular dystrophy in sheep in Paraíba.] Distrofia muscular nutricional em ovinos na Paraíba. Pesquisa Veterinária Brasileira 25(2):120-124. Centro de Saúde e Tecnologia Rural, UFCG, Campus de Patos, 58700-000 Patos, PB Brazil. E-mail: riet@cstr.ufcg.edu.br

An outbreak of nutritional muscular dystrophy is reported in the semiarid region of northeastern Brazil affecting 3-4 months old Dorper sheep. The animals, weighing 30-40 kg, were fed ad libitum with milk, concentrated ration, Tifton hay, and a mineral mixture. Six out of 70 lambs were affected and died in the first 48 hours after the onset of the outbreak. Clinical signs were fever of $40-41^{\circ} \mathrm{C}$, incoordination followed by paralysis and recumbence, depression, prostration with decreased pupillary and corneal reflexes, decreased tonus of the tongue and maxilla, salivation, submaxillar edema, and increased cardiac and respiratory rates. Death occurred after a clinical manifestation period of 6-12 hours. At necropsy of three animals, skeletal muscles were pale, the liver was yellowish and enlarged, the parotid, submaxillary, retropharyngeal, prescapular and mediastinal lymph nodes were enlarged with red surface, and red areas were observed on the lung surface. On histology, segmental muscular necrosis was observed in all skeletal muscles examined. The liver had centrilobular fatty degeneration, and congestion was observed in the lung and lymph nodes. From 48-96 hours after the begin of the outbreak, another 3 animals were affected. They were treated with Vitamin A, E and D complex; two of them died and one survived. On the same farm, a flock of 20 Santa Inês sheep of the same age as the affected animals, fed with the same food, but no milk, and another 900 sheep of different ages were not affected. The over nutrition of sheep with fast growing rates, and the stress caused by two days of water restriction to improve milk consumption had been predisposing factors for the occurrence of the disease. It is also possible that some of the minerals supplemented interfered with selenium availability.
\end{abstract}

INDEX TERMS: Nutritional muscular dystrophy, muscular segmental necrosis, selenium and vitamine E deficiency, sheep.

RESUMO.- Descreve-se um surto de distrofia muscular nutricional em ovinos no semi-árido Nordestino. Foram afetados animais de 3-4 meses de idade, da raça Dorper, pesando 30$40 \mathrm{~kg}$. Os animais eram alimentados, à vontade, com leite, ração balanceada, capim Tifton e sal mineral. Dos 70 animais Dorper, 6 adoeceram e morreram em um período de 48 horas. Apresentaram temperatura, entre 40 e $41^{\circ} \mathrm{C}$, incoordenação com posteri-

\footnotetext{
${ }^{1}$ Recebido em 1 de dezembro de 2004.

Aceito para publicação em 11 de fevereiro de 2005.

2 Aluno do Programa de Pós-Graduação em Pequenos Ruminantes, Universidade Federal de Campina Grande (UFCG).

${ }^{3}$ Médico Veterinário Autônomo.

${ }^{4}$ Curso de Medicina Veterinária, Centro de Saúde e Tecnologia Rural, UFCG, Campus de Patos, Patos, PB 58700-000. *Autor para correspondência. E-mail: riet@cstr.ufcg.edu.br
}

or paralisia e decúbito, depressão, prostração e diminuição dos reflexos pupilar e de ameaça, flacidez da língua e mandíbula, salivação, edema submandibular, dispnéia e aumento da frequiência cardíaca. A morte ocorreu após curso clínico de 6- 12 horas. Na necropsia de 3 animais, os músculos esqueléticos estavam de coloração pálida, o fígado estava aumentado de volume e de coloração amarelada, os gânglios parotídeos, submandibulares, retrofaríngeos, prescapulares e mediastínicos estavam aumentados de volume e avermelhados e os pulmões apresentavam áreas vermelhas. Na histologia havia necrose segmentar de todos os músculos examinados e congestão dos gânglios linfáticos e pulmão. Posteriormente mais três animais adoeceram, sendo tratado com oxitetraciclina e complexo vitamínico A,D e E. Desses 3 animais, 2 morreram e um sobreviveu. Na mesma fazenda havia e não adoeceram 20 ovinos da raça Santa Inês, da mesma idade que os animais afetados, que recebiam a mesma 
alimentação exceto o leite, e 900 ovinos de outras idades. A superalimentação em animais com rápido crescimento e o estresse causado pela restrição de água durantes 2 dias, para aumentar o consumo de leite, parecem ter sido fatores predisponentes para a ocorrência da doença. É possível, também, que algum dos minerais suplementados tenha antagonizado o Se presente na alimentação.

TERMOS DE INDEXAÇÃO: Distrofia muscular nutricional, necrose segmentar muscular, deficiência de selênio e vitamina $\mathrm{E}$, ovinos.

\section{INTRODUÇÃO}

A distrofia muscular nutricional (DMN) ou doença do músculo branco é uma afecção miodegenerativa hiperaguda, aguda ou subaguda dos músculos cardíaco e/ou esqueléticos causada pela carência de vitamina E e selênio. A doença é caracterizada por necrose segmentar com calcificação de segmentos necróticos das fibras musculares (Mass et al. 1994). A doença ocorre em animais mantidos em pastos cujos solos são pobres em Se e vitamina $E$ ou que recebem rações deficientes nesses elementos. Geralmente, há fatores precipitantes da enfermidade, que incluem crescimento rápido e/ou um fator dietético como excesso de ácidos graxos insaturados na alimentação (Barros 2001, Radostits et al. 2002). Fatores estressantes, como a manutenção dos animais ao ar livre após períodos de estabulação durante o inverno, caminhadas de longa distância e manejo do rebanho para a vacinação e outras práticas são, também, predisponentes à ocorrência da distrofia muscular nutricional (Radostits et al. 2002).

A vitamina E e o Se atuam como protetores das membranas celulares contra estresse oxidativo. O Se é um cofator da enzima antioxidante glutationa peroxidase, responsável pela neutralização dos efeitos tóxicos do peróxido de hidrogênio no citossol, enquanto que a vitamina $\mathrm{E}$ atua na prevenção da lipoperoxidação das membranas biológicas (Maas et al. 1994, Barros 2001, Radostits et al. 2002). Se o organismo é privado desses mecanismos, as membranas celulares têm a sua permeabilidade alterada, permitindo o influxo de cálcio para o citossol. Isso resulta na acumulação de cálcio nas mitocôndrias e morte celular, causando necrose segmentar (Barros 2001).

O Se e a vitamina E são encontrados em vários tecidos do organismo e suas deficiências podem ocasionar vários problemas para a saúde dos animais, incluindo alterações reprodutivas (retenção de placenta, reabsorção fetal, distocia), aumento da susceptibilidade à infecções por redução da função dos neutrófilos, diminuição na produtividade animal e morte por distrofia muscular nutricional (Smith \& Sherman 1994, Radostits et al. 2002).

A distrofia muscular nutricional ocorre na maioria dos países do mundo, sendo mais comum no Reino Unido, Estados Unidos, Europa, Austrália e Nova Zelândia (Smith et al. 1994, Pugh 2002, Radostits et al. 2002). Na Nova Zelândia, um grupo de doenças (emagrecimento em cordeiros, infertilidade em ovelhas com alta mortalidade embrionária entre a $3^{\underline{a}}$ e a $4^{\underline{a}}$ semanas após a concepção, e diarréia em ovelhas lactantes) é conhecido como responsivo a selênio, por que os animais se recuperam após a suplementação com este mineral (Radostits et al. 2002).
No Brasil a primeira ocorrência da distrofia muscular nutricional foi registrada no Rio Grande do Sul, em pastagens de Lolium multiflorum (azevém), onde morreram 40 de 140 bezerros de um ano de idade (Barros et al. 1988). A doença foi diagnosticada, também, em caprinos confinados no Rio Grande do Sul e em ovinos confinados na Paraíba. No Rio Grande do Sul, os caprinos de diversas idades estavam confinados durante o inverno recebendo silagem de sorgo, feno de alfafa, feno de azevém, rolão de milho e pouca quantidade de ração para caprinos (Loretti et al. 2001). Posteriormente, casos esporádicos foram observados em cabras e também em cabritos jovens, sempre associados ao confinamento durante o inverno (David Driemeier 2003). Na Paraíba foi observado um surto de distrofia muscular nutricional em ovinos de 4 meses, confinados, com rápido crescimento, recebendo ração rica em proteína e energia (Riet-Correa et al. 2003).

Amorim et al. (2003) relataram em Botucatu, SP, dois casos de DMN em bovinos Nelore, provenientes de uma mesma propriedade, após o manejo durante a castração. Ambos foram tratados com acetato de DL-a-tocoferol (300 UI por $45 \mathrm{~kg}$ peso vivo), e selenito de sódio (6 mg / $45 \mathrm{~kg} / \mathrm{pv}$ ) pela via intramuscular. Um animal se recuperou, o outro não apresentou melhora sendo eutanasiado e necropsiado. Na necropsia e na histopatologia foi confirmado o diagnóstico.

Concentrações baixas de Se foram encontradas no soro de bovinos em São Paulo (Lucci et al. 1984a). Amostras de pastagens de São Paulo, Mato Grosso e Mato Grosso do Sul e em amostras de milho provenientes de diversas regiões do País apresentaram, também, baixas concentrações de Se. (Lucci et al. 1984a, Lucci 1997, Tokarnia et al. 1998, 1999, McDowell 2000).

Este trabalho teve como objetivo relatar um surto de DMN em ovinos no município de Campina Grande, estado da Paraíba, Brasil.

\section{MATERIAL E MÉTODOS}

Os dados epidemiológicos foram obtidos na fazenda onde estava ocorrendo o surto, e os sinais clínicos foram observados em 6 animais que adoeceram em um período de 48 horas. Três ovinos foram necropsiados. Amostras de fígado, coração, pulmão, rim, baço, linfonodos, músculos (diafragma, glúteos, psoas e língua), assim como encéfalo e medula foram fixados em formol a $10 \%$. No sistema nervoso central, seções do córtex frontal, parietal, temporal e occipital, núcleos da base e cápsula interna, mesencéfalo à altura do colículo rostral, cerebelo, pedúnculos cerebelares, ponte, medula oblonga e medula cervical, torácica e lombar foram estudadas histologicamente. Para o estudo histológico fragmentos dos diferentes órgãos foram processados rotineiramente e corados pela hematoxilina-eosina. Amostras de fígado, pulmão, linfonodos e cérebro foram coletadas em sacos plásticos estéreis, conservados sob refrigeração, semeados em Agar Chocolate e Agar Sangue e incubados em aerobiose e microaerofilia por até 72 horas para análise microbiológica.

\section{RESULTADOS}

A doença ocorreu em um grupo de 70 ovinos, Dorper, originados de embriões importados da África do Sul, de 3-4 meses de idade, de ambos os sexos, pesando aproximadamente $30-40 \mathrm{~kg}$, que haviam sido desmamados aos 55 dias de vida. Logo após o 
desmame, os 70 animais eram alimentados com 40 litros de leite diários, que após 10 dias foi aumentado para 80 litros e após 20 dias para 120 litros. Além do leite, que era fornecido em cochos, os animais recebiam $150 \mathrm{~g}$ de ração, que foi aumentado gradualmente, chegando a $700 \mathrm{~g}$ de ração por cabeça por dia. Na fazenda havia aproximadamente 1.000 ovinos de diferentes idades, sendo 120 da raça Dorper e os restantes da raça Santa Inês. Vinte cordeiros da raça Santa Inês estavam recebendo a mesma ração, na mesma quantidade, que os cordeiros da raça Dorper, mas não recebiam leite.

A ração fornecida aos animais era constituída por farelo de milho, farelo de soja e farelo de trigo e feno de capim Tifton. Trinta dias após o desmame, uma nova ração, contendo $18 \%$ de proteína, $13 \%$ de umidade, $10 \%$ de matéria fibrosa, $9 \%$ de matéria mineral, 3,5\% de extrato etéreo, $1,8 \%$ de cálcio e $0,55 \%$ de fósforo, foi acrescentada à alimentação sendo misturada a $80 \%$ com a ração anterior. A alimentação era administrada em duas partes, uma pela manhã e outra pela tarde (às 6 horas e às 17 horas). Após receber a primeira alimentação de concentrado, os ovinos eram colocados em pequenos piquetes de capim Tifton e à tarde eram recolhidos para as instalações. Os animais recebiam, também, um suplemento mineral à vontade (Purinofós 65 Plus da Purina) contendo $140 \mathrm{~g}$ de Ca, $65 \mathrm{~g}$ de $\mathrm{P}, 15 \mathrm{~g}$ de $\mathrm{S}, 15 \mathrm{~g}$ de $\mathrm{Mg}$, $3.500 \mathrm{mg}$ de $\mathrm{Zn}, 3.000 \mathrm{mg}$ de manganês, $60 \mathrm{mg}$ de iodo, $10 \mathrm{mg}$ de Se, $100 \mathrm{mg}$ de Co e $50.000 \mathrm{UI} / \mathrm{kg}$ de vitamina A.

Todos os borregos eram filhos de ovelhas vacinadas para clostridioses, raiva e leptospirose e foram vacinados aos 40 e 60 dias de idade contra clostridioses e aos 50 dias contra raiva. Vinte dias após o desmame, os animais sofreram restrição de água por 2 dias, para que consumissem o leite que era fornecido. A água consumida pelos animais era de um açude que por tubulação chegava a uma cisterna onde era tratada com cloro e, posteriormente, distribuída para os cochos de alvenaria que estavam distribuídos por toda propriedade. As instalações eram cobertas e protegidas de vento.

Dos 70 animais Dorper, seis adoeceram e morreram em um período de 48 horas. Posteriormente, entre 48 e 96 horas após o início do surto, adoeceram mais 3 animais, que foram tratados com oxitetraciclina na dose de $1 \mathrm{ml}$ por $10 \mathrm{~kg}$ de peso vivo, em dose única, e com uma dose de $4 \mathrm{ml}$ de um complexo vitamínico contendo 25.000.000 UI de vitamina A, 7.000.000 UI de vitamina $D$ e 7.000 UI de vitamina E por cada $100 \mathrm{ml}$. Desses três animais, dois morreram e um sobreviveu. Os 6 animais que adoeceram e morreram apresentaram temperatura entre 40 e $41^{\circ} \mathrm{C}$, debilidade muscular, dificuldade de ficar em estação, tremores musculares, incoordenação com posterior paralisia e decúbito, depressão, prostração e diminuição dos reflexos pupilares e de ameaça, flacidez da língua e mandíbula, salivação, edema submandibular, dispnéia e aumento da freqüência cardíaca. A morte ocorreu após curso clínico de 6-12 horas. Dos 3 ovinos necropsiados um tinha morrido 4 horas antes (Ovino 1), outro no dia anterior (Ovino 2) e o último imediatamente antes da necropsia (Ovino 3). Na necropsia os músculos esqueléticos estavam pálidos, o fígado estava aumentado de volume, de coloração irregular, amarelado em algumas áreas e com aumento do padrão lobular em outras. O pulmão apresentava extensas áreas vermelhas entre áreas normais, tanto nos lóbulos anteriores

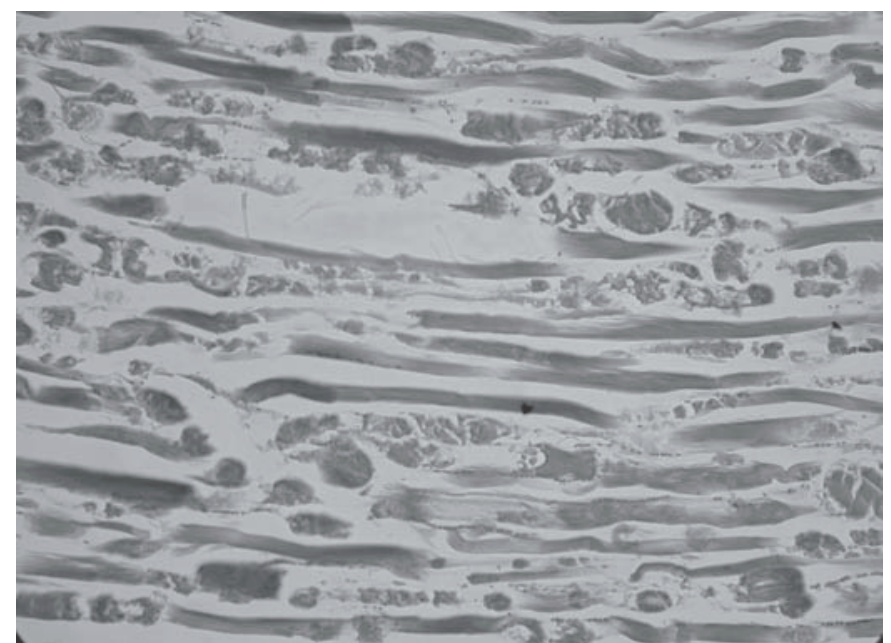

Fig. 1. Músculo esquelético (psoas) com necrose segmentar muscular, observando-se numerosos segmentos de fibras com necrose, assim como fibras eosinofílicas com perda das estriações (Ovino no 3 ). HE, obj. 20.

quanto nos caudais. As áreas vermelhas eram superficiais estendendo-se somente 1-2 mm dentro do parênquima. Os Ovinos $1 \mathrm{e}$ 2 apresentavam hemorragias petequiais na pleura e pericárdio. Foram observados avermelhamento e aumento de volume dos linfonodos parotídeos, submandibulares, retrofaríngeos, prescapulares e mediastínicos. No sistema digestivo não foram observadas lesões nos 3 animais, exceto o primeiro que apresentava conteúdo ruminal compactado e mucosa do abomaso avermelhada. Os demais órgãos não apresentaram lesões significativas.

Não houve crescimento de bactérias de significado patológico nas amostras de fígado, pulmão, linfonodos e cérebro.

Na histologia observou-se necrose segmentar de todos os músculos examinados, (glúteos, psoas, língua e coração); esses achados eram caracterizados por perda das estriações, aumento de volume e ruptura das fibras musculares, tumefação e hiperplasia dos núcleos sarcolemais e discreta infiltração de macrófagos (Fig. 1). No coração do Ovino 3 algumas fibras se apresentavam eosinofílicas com os núcleos picnóticos. Observaram-se degeneração gordurosa do fígado, de preferência centrolobular, e congestão pulmonar e dos linfonodos parotídeos, submandibulares, retrofaríngeos, prescapulares e mediastínicos. Os demais órgãos não apresentaram lesões significativas.

\section{DISCUSSÃO}

A necrose segmentar muscular observada nos ovinos afetados é característica da distrofia muscular nutricional. Outras doenças que poderiam causar necrose segmentar são as miopatias tóxicas como as intoxicações por Senna occidentalis e antibióticos ionóforos; no entanto, ambas foram descartadas, uma vez que não foram encontradas sementes de $S$. occidentalis na alimentação e não haviam sido administrados antibióticos ionóforos na ração. Por outro lado, a doença não afetou cordeiros da raça Santa Inês que estavam recebendo a mesma ração, nem ovinos de outras idades tanto da raça Dorper, quanto da raça Santa Inês 
que também estavam recebendo o mesmo concentrado. Deve ser realizado também, o diagnóstico diferencial de doenças neurológicas agudas como a pasteurelose septicémica e a infecção por Haemophilus agni (Histophilus ovis), já que os animais apresentaram sinais que podem ser confundidos com a sintomatologia nervosa observada nessas doenças, no entanto os exames microbiológicos deram resultados negativos. Outras doenças neurológicas como raiva, botulismo, listeriose e polioencefalomalacia, devem ser consideradas, também, no diagnóstico diferencial.

O rápido crescimento dos animais que estavam confinados, superalimentados, recebendo ração comercial e leite em altas quantidades foi, aparentemente, a principal causa para a ocorrência da doença. $O$ estresse sofrido devido à restrição de água por dois dias, para que os animais consumissem o leite fornecido no coxo, pode ter atuado, também, como fator desencadeante. Na Paraíba, um surto semelhante foi diagnosticado em ovinos, também da raça Dorper, com 4 meses de idade. Esses animais estavam confinados recebendo ração altamente protéica e energética e há poucos dias tinham sido submetidos a estresse de manejo sanitário (Riet-Correa et al. 2003). O diagnóstico da DMN chama a atenção para a provável importância desta doença em ovinos confinados na Paraíba, principalmente animais em preparação para exposições que recebem alimentação em grandes quantidades. Também chama a atenção a ocorrência da doença exclusivamente em cordeiros da raça Dorper, o que pode ter ocorrido devido ao rápido crescimento destes animais quando comparados com outras raças de ovinos criados na região Nordeste.

Outro fator que pode ter participado na ocorrência da doença é a presença de antagonistas do Se na alimentação. Vários metais como, prata, cobre, cobalto, cádmio, mercúrio e ou estanho podem antagonizar o Se (Jones et al. 1997). Uma alta ingestão de fósforo aumenta a gravidade da DMN e diminui o teor de Se hepático em ovinos (Pugh 2002). Da mesma forma a aplicação de nitrogênio e enxofre na forragem pode interferir na absorção de Se pelas forragens e precipitar a doença nos ruminantes (Hulland 1993, Pugh 2002). Na Austrália, a doença em caprinos tem sido associada a regiões onde o solo é ácido e com aplicações de superfosfato como fertilizante (Smith et al. 1994). De todos os minerais citados acima, o cobalto e o enxofre estavam incluídos no sal mineral, enquanto que o cálcio e o fósforo estavam tanto no sal mineral quanto na ração. Apesar de que não foi determinado o consumo de sal mineral pelos ovinos este sal continha quantidades adequadas de Se. É possível que os animais não estivessem consumindo quantidades suficientes de sal mineral ou que o consumo de outros minerais tenha antagonizado o Se suplementado. Esse fato evidencia a importância de uma suplementação mineral adequada para a profilaxia da enfermidade.

A doença teve um curso superagudo, caracterizado por insuficiência muscular e hipertermia, a qual provavelmente está relacionada com o aumento de trabalho muscular associado ao esforço respiratório (Maas et al. 1994). Embora a literatura descreva a doença superaguda como causada por lesões cardíacas, neste caso, as lesões mais graves foram encontradas nos músculos esqueléticos e os sinais clínicos observados foram devido ao comprometimento dessa musculatura. A eosinofilia e presença de núcleos picnóticos, observadas no músculo cardíaco de um animal, podem ser observadas, também, em animais normais (Stigger et al. 2001) e não foram consideradas como lesão. As lesões foram difusas em todos os músculos esqueléticos avaliados, o que sugere que outros músculos, que não foram estudados apresentavam, também, lesões. Na histologia dos músculos esqueléticos a necrose segmentar foi difusa, mas sem calcificação. A calcificação é um achado característico na DMN (Hulland 1993, Jones et al. 1997, Pugh 2002). Nestes casos, a ausência da calcificação deve-se, provavelmente, ao rápido curso clínico da doença nos animais necropsiados. A degeneração gordurosa do fígado, uma lesão que não teve participação na morte dos animais, é devida, provavelmente, à superalimentação com concentrados e leite.

Para o tratamento da DMN recomenda-se a administração intramuscular de uma mistura contendo por cada $\mathrm{ml}, 3 \mathrm{mg}$ de selênio (como selenito de sódio ou potássio) e 150 UI de acetato de DL--tocoferol, na dose de $2 \mathrm{ml} / \mathrm{kg}$ de peso corporal (Barros 2001). O tratamento deve ser preventivo, pois animais afetados raramente se recuperam, o que aconteceu em um dos três casos tratados com vitamina $\mathrm{E}$.

A prevenção e o controle da DMN são obtidos mediante a suplementação de Se e vitamina E, sendo que a suplementação com Se é mais barata e mais fácil de ser realizada que a suplementação com vitamina E. O Se deve ser fornecido no sal mineral de pequenos ruminantes em pastagens e na ração de animais confinados. Essa suplementação reduz o aparecimento da DMN e da retenção de placenta, aumentando os seus níveis no colostro e no leite (Radostits et al. 2002). O selênio poderá ser incorporado na ração de ruminantes até um nível de 0,3 ppm e o sal mineral para ovinos deverá conter 30 ppm de Se (Maas et al.1994). O Se pode ser suplementado, também, em forma injetável. Injeções de $1 \mathrm{mg}$ de Se na forma de selenato de bário em ovelhas mantém níveis adequados de Se por até 5 meses (Radostits et al. 2002). A alimentação dos animais com feno e cereais adequadamente preparados e armazenados, ou o acesso a forragens verdes de alta qualidade deverão proporcionar apropriada ingestão de vitamina $\mathrm{E}$ (Maas et al. 1994).

Os resultados deste trabalho alertam para os riscos da ocorrência de doenças nutricionais em animais de alto valor zootécnico, superalimentados com o objetivo de serem comercializados para reprodução. Além da distrofia muscular nutricional muscular, outras doenças são freqüentes no semiárido em ovinos e caprinos alimentados com mais de 1,5\% do peso vivo de concentrados: acidose crônica ou aguda, polioencefalomalacia, urolitiase, intoxicação crônica por cobre em ovinos e osteodistrofia fibrosa em caprinos. Outro fator que deve ser levado em consideração é uma suplementação mineral adequada já que na região semi-árida o que se constata é a recomendação de misturas minerais denominadas "completas" durante todo o ano, indiscriminadamente, tanto para animais a pasto quanto para animais confinados ou semi-confinados. No caso de animais confinados e suplementados com grãos não se recomenda administrar sal mineral e sim a suplementação dos grãos com $0,25 \%$ a $0,5 \%$ de $\mathrm{NaCl}$ e $1 \%$ a $1,5 \%$ de carbonato de Ca. O Se deve também ser administrado aos 
animais confinados, principalmente quando estão recebendo feno de baixa qualidade.

Agradecimentos.- Este trabalho foi financiado pelo Programa de Apoio a Núcleos de Excelência - PRONEX, Projeto no 0145/03, FAPESQ/MCT/ CNPq.

\section{REFERÊNCIAS}

Amorim R.M., Marcondes J.S., Borges A.S., Gonçalves R.C. \& Chiacchio S.B. 2003. Distrofia muscular nutricional em bovinos. Anais $11^{\circ}$ Congr. Latinoamericano de Buiatria, Salvador, p.41-42. (Resumo)

Barros C.S.L. 2001. Deficiência de selênio e vitamina E, p.312-320. In: Riet-Correa F., Schild A.L., Mendez M.C. \& Lemos R.R.A. (ed.) Doenças de Ruminantes e Eqüinos. Vol. 2. 2ª ed. Varela Editora e Livraria, São Paulo.

Barros C.S.L., Barros S.S., Santos M.N. \& Metzdorf L.L. 1988. Miopatia nutricional em bovinos no Rio Grande do Sul. Pesq. Vet. Bras. 8(3/4):5155.

Driemeier D. 2003. Comunicação pessoal (Universidade Federal do Rio Grande do Sul, Porto Alegre).

Hulland T.J. 1993. Muscle and tendon, p.230-234. In: Jubb K.V.F., Kennedy P.C. \& Palmer N. (ed.) Pathology of Domestic Animals. Vol.1. 4th ed. Academic Press, Diego.

Jones T.C., Hunt R.D. \& King N.W. 1997. Patologia Veterinária. 6 6 ed. Manole, São Paulo, p.830-850.

Loretti A.P., Driemeier D., Traverso S.D. \& Seitz A.L. 2001. Miopatia nutricional em caprinos no Rio Grande do Sul. Anais $10^{\circ}$ Encontro Nacional de Patologia Veterinária, Pirassununga, SP, p.36. (Resumo)

Lucci C.S. 1997. Nutrição e Manejo de Bovinos Leiteiros. Manole, São Paulo. 169p.

Lucci C.S., Moxon A.L., Zannetti M.A., Fukishima R.S., Schalch E. \& Pettinati R.L. 1984a. Selênio em bovinos leiteiros no Estado de São Paulo. I.
Níveis de selênio em soros sangüíneos. Revta Fac. Med. Vet. Zootec. USP 21(1):65-70.

Lucci C.S., Moxoton A. L., Zanetti M.A., Fukushima R.S., Schalch E. \& Pettinati R. L 1984b. Selênio em bovinos leiteiros do estado de São Paulo. II. Níveis de selênio nas forragens e concentrados. Revta Fac. Med. Vet. Zootec. USP 21(1):71-76.

Maas J., Parish S.M. \& Hodopson D.R. 1994. Miodegeneração nutricional, p.1335-1351. In: Smith B.P. (ed.) Tratado de Medicina Interna de Grandes Animais. Manole, São Paulo.

McDowell L.R. 2000. Minerais para Ruminantes sob Pastejo em Regiões Tropicais, Enfatizando o Brasil. $3^{\underline{a}}$ ed. University of Florida, Gainesville. $92 \mathrm{p}$.

Pugh D.G. 2002. Sheep and Goat Medicine. 1st ed. W.B. Saunders Company, Philadelphia, p.223-255.

Radostits E.M., Gay C.C., Blood D.C. \& Hinchcliff K.W. 2002. Deficiência de selenio e vitamina E. Clínica Veterinária. 9aㅗ ed. Guanabara Koogan, São Paulo, p.1364-1384.

Riet-Correa F., Tabosa I.M., Azevedo E.O., Medeiros R.M., Simões S.V.D., Dantas A.F., Alves C.J., Nobre V.M.T., Athayde A.C., Gomes A.A. \& Lima E.F. 2003. Doenças dos ruminantes e eqüinos no semi-árido da Paraíba. Semi-Árido em Foco, Patos, 1(1):2-86.

Smith M.C. \& Sherman D.M. 1994. Goat Medicine. Lea \& Febiger, Philadelphia, p.535-540.

Stigger A.L., Barros C.S.L., Langohr I.M., \& Barros S.S. 2001. Intoxicação experimental por Ateleia glazioviana (Leg.Papilionoideae) em ovinos. Pesq. Vet. Bras. 21:98-108

Tokarnia C.H., Döbereiner J. \& Moraes S.S. 1998. Situação atual e perspectivas da investigação sobre nutrição mineral em bovinos no Brasil. Pesq. Vet. Bras. 8(1/2):1-16.

Tokarnia C.H., Döbereiner J., Moraes S.S. \& Peixoto P.V. 1999. Deficiências e desequilíbrios minerais em bovinos e ovinos, revisão dos estudos realizados no Brasil de 1987 a 1998. Pesq. Vet. Bras. 19(2):47-62. 